\title{
Otimização da produção de álcool de mandioca
}

\author{
Optimizing of alcohol production from manioc starch
}

\author{
José Carlos CURVELO-SANTANA ${ }^{1,2}$, Daniela Diniz EHRHARDT ${ }^{1}$, Elias Basile TAMBOURGI ${ }^{1 *}$
}

\section{Resumo}

Este trabalho objetivou otimizar o processo de hidrólise do amido de mandioca com $\alpha$-amilase de $A$. niger e obter o álcool deste xarope. Os ensaios foram realizados a $\mathrm{pH} 4,8$; em que variaram-se a concentração do amido (entre 7-22 g. $\mathrm{L}^{-1}$ ) e a temperatura (entre $30-59,1^{\circ} \mathrm{C}$ ). Durante a fermentação, usaram-se nos mostos 2,2 e $5 \%$ de amido de mandioca. Os resultados da hidrólise mostraram que o tempo ficou entre 20-200 minutos; a análise RSM mostrou que o rendimento diminuiu nas concentrações médias; e as condições ótimas foram encontradas entre $55-59,1^{\circ} \mathrm{C}$ e com a concentração entre 7,9-10 ou 20-22 g. $\mathrm{L}^{-1}$, em que se hidrolisou $80 \%$ do amido. A melhor condição de fermentação foi obtida para o mosto contendo $5 \%$ de amido. Sua composição final foi de 0,668 g.L. $\mathrm{L}^{-1}$ de ART, 0,572 g.L $\mathrm{L}^{-1}$ e de AR, $3,71^{\circ} \mathrm{GL}$. O rendimento alcoólico foi de $45 \%$, demonstrando que este processo é uma alternativa eficiente à indústria sucroalcooleira.

Palavras-chave: amido; hidrólise; Manihot sp.; amilases; álcool; otimização RSM.

\begin{abstract}
The objective of this study was the optimization of the manioc root starch hydrolysis by a-amylase from A. niger and alcohol production from this starch syrup. Hydrolysis assays were performed at $\mathrm{pH} 4.8$, the starch concentration and the temperature varied from 7 to 22 g.L $\mathrm{L}^{-1}$, and 30 to $59.1{ }^{\circ} \mathrm{C}$, respectively. The starch contents during the syrup fermentation were 2.2 and $5 \%$. The results of the starch hydrolysis showed that the hydrolysis time was between 20-200 minutes, the RSM analysis showed a decrease in the starch yield at the average concentration and above of $70 \%$ at high temperatures, and the optimal conditions were found at temperature between $55-59.1{ }^{\circ} \mathrm{C}$ and concentration between 7.9-10 or $20-22$ g. $\mathrm{L}^{-1}$; conditions at which $80 \%$ of the starch was hydrolyzed. The best fermentation condition was obtained for the must containing $5 \%$ of starch. The final fermentation composition obtained was of 0.68 g.L.- ART and 0.572 g.L ${ }^{-1}$ AR. After the fermentation process, an alcohol yield of $45 \%$ was obtained showing that this process is a very good alternative for sugar-alcohol industries.
\end{abstract}

Keywords: starch; hydrolysis; Manihot sp.; amylases; alcohol; RSM optimization.

\section{Introdução}

O etanol voltou a ocupar um lugar de destaque no cenário energético do país e do mundo. No caso brasileiro, o álcool renasceu com o surgimento dos carros bicombustíveis, além das várias manifestações de governos e empresas, que mostraram o potencial de mercado e da tecnologia de produção de etanol (OLIVEIRA; VASCONCELOS, 2006). Um dos desafios do Brasil é aumentar a oferta de álcool combustível e buscar novas fontes e/ou métodos para produção de álcool.

Uma alternativa à substituição desta matéria-prima é o uso de xaropes obtido a partir da hidrólise de amido. O emprego do amido para produção de álcool levará ao desenvolvimento agroindustrial das regiões Norte e Nordeste, que são as maiores produtoras de mandioca (Manihot spp.) do Brasil, e para todas as regiões brasileiras que têm tradição no cultivo de milho (Zea mays) e arroz (Oriza sativa) e outros amiláceos (FERREIRA et al., 2005, 2006; LEONEL; CEREDA, 2000; MENEZES, 1980). Essas matérias-primas, contudo, não são diretamente fermentáveis, necessitando de uma hidrólise prévia de suas cadeias.
A hidrólise enzimática apresenta vantagens sobre a ácida por ser seletiva, gastar pouca energia e não gerar produtos indesejáveis. As enzimas mais empregadas para este propósito são principalmente as $\alpha$ e $\beta$-amilases que são encontradas em diversas fontes, como cereais (cevada, milho, trigo, arroz, etc.) e micro-organismos (FOGARTY; KELLY, 1979; WISEMAN, 1987).

Desta forma, neste trabalho, foi feita a otimização por análise de superfície de resposta, da hidrólise do amido de mandioca por $\alpha$-amilase fúngica (A. niger) a pH 4,8, verificandose os efeitos da temperatura e concentração de amido sobre o rendimento do processo e a aplicação do xarope obtido na melhor condição de hidrólise na produção de álcool via fermentação com S. cerevisiae.

\subsection{O Amido e suas fontes naturais}

Quimicamente o amido e a fécula são constituídos de glicose, unidos por ligações na forma a-glicosídicas. As ligações

Recebido para publicação em 14/4/2008

Aceito para publicação em 7/7/2009 (003436)

${ }^{1}$ Departamento de Engenharia de Sistemas Químicos, Faculdade de Engenharia Química, Universidade Estadual de Campinas - UNICAMP,

Cidade Universitária "Zeferino Vaz", Av. Albert Einstein, n. 500, CP 6066, CEP 13083-970, Barão Geraldo, Campinas - SP, Brasil, E-mail: eliastam@feq.unicamp.br

${ }^{2}$ Departamento de Ciências Exatas, Universidade Nove de Julho - UNINOVE, Rua Vergueiro, n. 235/249, Liberdade, CEP 01504-001, São Paulo - SP, Brasil

${ }^{*}$ A quem a correspondência deve ser enviada 
do tipo $\alpha$ são mais facilmente hidrolisadas do que as do tipo $\beta$, o que torna o uso do amido potencialmente mais interessante como substrato de processos biossintéticos. Do ponto de vista estrutural, o amido é formado por polímeros, dentre os quais predomina a amilose, formada por moléculas de glicose unidas por ligações glicosídicas $\alpha-1,4$, que lhe dão configuração retilínea e amilopectina, polímero de maior peso molar, em que as moléculas de glicose em ligações $\alpha-1,4$ e $\alpha-1,6$ proporcionam configuração espacial ramificada (LIMA et al., 2001; REGULY, 2000). Na Tabela 1, mostra-se a composição de amidos naturais para alguns produtos.

A Tabela 2 apresenta o rendimento em álcool de algumas fontes de carboidratos. Dentre estes vegetais se destacam, no Brasil: a mandioca (Manihot sp.) e o milho (Zea mays). A primeira, como fonte de amido preponderantemente industrial e de preparo de farinha de mesa; o segundo, como fonte de amidos modificados para a indústria de alimentação e outros fins técnicos (REGULY, 1996, 1998). Como se nota, nesta tabela, uma tonelada de mandioca supera entre 2-3,4 vezes a quantidade de álcool produzido pela cana-de-açúcar.

\section{Material e métodos}

\subsection{Farelo de mandioca}

Este foi doado pelo Laboratório de Processos de Separação do Departamento de Engenharia Química da Universidade Federal de Sergipe, e sua composição, em termos de amido, fornecida pelo mesmo laboratório foi de $71,65 \%$ da massa seca de farelo de mandioca.

\subsection{Enzima}

As amilases usadas foram do tipo FORILASE NTL ${ }^{\circ}$, fornecida pela COGNIS (São Paulo, Brasil). Estas enzimas são indicadas pelo produtor para uso em processos de degomação em indústrias têxteis. Para o uso nos biorreatores ela foi diluída em cinco vezes ( $100 \mu \mathrm{L}$ do produto enzimático para cada $400 \mu \mathrm{L}$ de água deionizada).

Tabela 1. Composição aproximada de amidos naturais.

\begin{tabular}{lcc}
\hline \multicolumn{1}{c}{ Produto natural } & \% amilose & $\%$ amilopectina \\
\hline Amido de milho & $24,0-27,0$ & 70 \\
Amido de arroz & $15,0-18,5$ & 79 \\
Amido de trigo & $20,0-25,0$ & 80 \\
Amido de mandioca & $16,7-25,0$ & 80 \\
\hline Fonte: Reguly (1996). & &
\end{tabular}

Tabela 2. Matérias-primas e rendimento em álcool.

\begin{tabular}{lc}
\hline Matéria-prima & Produção de álcool (L/tonelada) \\
\hline Cana moída & $72-86$ \\
Melaço & $300-380$ \\
Mandioca & $142-250$ \\
Milho & $330-380$ \\
Sorgo & $350-400$ \\
\hline
\end{tabular}

Fonte: Reguly (1998).

\subsection{Determinação do teor de Açúcares Redutores (AR) $e$ Redutores Totais (ART)}

$\mathrm{O}$ teor de $\mathrm{AR}$ (ou concentração de glicose gerada, $\mathrm{C}_{\text {Glicose }}$ ) foi determinado pelo método do Miles Laboratory (método do DNS), apresentado em Reguly (1996) e Biazus et al. (2005). Para a determinação do ART, antes da análise pelo método do DNS, a amostra passou por um processo de hidrólise ácida, com $\mathrm{HCl} 1 \mathrm{M}$, por 15 minutos em banho-maria a $100^{\circ} \mathrm{C}$, seguida de neutralização com $\mathrm{NaOH} 1 \mathrm{M}$.

\subsection{Medição do teor de álcool}

Para se medir o teor alcoólico no mosto, inicialmente destilaram-se $100 \mathrm{~mL}$ deste e, usando-se o alcoômetro de Gay Lussac de $0-10^{\circ} \mathrm{GL}$ (INCOTERM, São Paulo), mediu-se o teor de álcool em ${ }^{\circ} \mathrm{GL}$. Também se usou o método densimétrico, que se baseia na medição da massa de um volume constante $(5 \mathrm{~mL})$ do destilado em balança analítica de precisão e se compara a uma curva de calibração feita previamente pela diluição de álcool etílico PA a 99,5\% de pureza em água deionizada (ASCAR, 1985; FERREIRA et al., 2005, 2006). Todos estes métodos foram realizados a $20{ }^{\circ} \mathrm{C}$ e ambos dão o teor alcoólico em \% (v/v), embora, neste trabalho, tenha-se usado esta unidade apenas para o método densimétrico.

\subsection{Avaliação do poder de hidrólise da enzima}

Biorreatores com aquecimento térmico, contendo amido solúvel nas concentrações do planejamento e a pH 4,8 em tampão acetato $0,1 \mathrm{M}$, foram usados em todos os experimentos. Para o estudo da hidrólise, os biorreatores continham $25 \mathrm{~mL}$ de solução de amido e a estes foram adicionados $500 \mu \mathrm{L}$ da solução enzimática. Após otimização, ampliou-se a escala dos biorreatores para $1 \mathrm{~L}$, mantendo-se as mesmas condições anteriores multiplicadas por um fator de $40(1000 \mathrm{~mL} / 25 \mathrm{~mL})$, para hidrólise e posterior fermentação. Montou-se um biorreator com a concentração de amido de mandioca na condição ótima de máximo $(2,2 \%$ de amido) e outro duplicando este valor (5\% de amido) para avaliar o efeito da concentração de amido na fermentação. Estas hidrólises ocorreram por 3 horas a $55^{\circ} \mathrm{C} \mathrm{e} \mathrm{pH} \mathrm{4,8} \mathrm{(CADOGAN;} \mathrm{HANKS,}$ 1995; FERREIRA et al., 2005, 2006; REGULY, 2000).

As concentrações de açúcares redutores (AR, dadas em glicose) foram medidas de tempo em tempo, para se obter a curva cinética para as devidas temperaturas e concentrações de amido usadas. O rendimento do processo de hidrólise $\left(\% R_{\text {Hidrólise }}\right)$ foi obtido pela concentração de amido hidrolisado $\left(C_{\text {AmidoHidrolisado }}\right)$ e a concentração de amido inicial $\left(C_{\text {Amido }}\right)$ ou a relação entre a glicose gerada $\left(\mathrm{C}_{\text {Glicose }}\right)$ e a concentração de glicose teórica $\left(C_{\text {Glicose Teórica }}=1,111^{\star} C_{\text {Amidolnicial }}\right)$, como se segue na Equação 1 (FERREIRA et al., 2005, 2006; SLEIMAN; VENTURI NETO, 2004):

$$
\% R_{\text {Hidrolise }}=\left(\frac{C_{\text {AmidoHidrolisado }}}{C_{\text {Amido }}}\right) * 100=\left(\frac{C_{\text {Glicose }}}{C_{\text {Glicose Teórica }}}\right) * 100
$$

\subsection{Fermentação do hidrolisado de mandioca}

Aos produtos obtidos da condição ótima de hidrólise nos biorreatores, foram adicionados $1 \mathrm{~g} . \mathrm{L}^{-1}$ de $\mathrm{NH}_{4} \mathrm{H}_{2} \mathrm{PO}_{4}, 0,1$ g.L. $\mathrm{L}^{-1}$ de $\mathrm{MgSO}_{4}$ e sacarose nas concentrações de 40 e $10 \mathrm{~g} \cdot \mathrm{L}^{-1}$ para o mostos contendo 2,2 e $5 \%$ de amido, respectivamente. Como 
o pH estava entre 4-5, não se necessitou ajustá-lo. Os mostos foram esterilizados por choque térmico. Três diluições das dornas principais foram feitas para facilitar a adaptação da levedura (do gênero Saccharomyces), que foram inoculadas no menor destes recipientes. Transferiram-se diariamente as diluições para as dornas seguintes (da menor para a maior) até que o inocular na a dorna principal, onde passou 12 dias fermentando. O teor alcoólico e de AR (em g glicose. $100 \mathrm{~mL}^{-1}$ ) foram medidos regularmente (ASCAR, 1985; FERREIRA et al., 2005, 2006; LIMA et al., 2001; REGULY, 1998) para acompanhar o desenvolvimento da fermentação. O rendimento da fermentação é dado pela Equação 2, que foi obtida da cinética de fermentação da glicose a álcool (FERREIRA et al., 2005, 2006; SLEIMAN; VENTURI NETO, 2004).

$$
\text { Rendimento }=\left(\begin{array}{l}
\frac{{ }^{\circ} G L \text { ou } \%(v / v) \text { do fermentado }}{0,795\left(\text { g.mL } L^{-1}\right)} \\
\left(\frac{180}{162}\right) *\left(\text { g amido. } 100 m L^{-1}\right)+ \\
+\left(\frac{2 * 180}{342}\right)\left(\text { gSacarose } 100 m L^{-1}\right)
\end{array}\right) * 100
$$

\subsection{Caracterização do fermentado}

Após o término da fermentação, foram determinados os teores de AR, ART, pelo método do Miles Laboratory (MILLER, 1959); de cinza, pelo método da calcinação a $500-600{ }^{\circ} \mathrm{C}$ por 6-8 horas; de extrato seco a $103-105^{\circ} \mathrm{C}$ por 6-8 horas; e os teores de álcool pelos métodos densimétricos e com o uso do alcoômetro Gay Lussac (ASCAR, 1985; FERREIRA et al., 2005, 2006).

\subsection{Planejamento fatorial da hidrólise}

Para avaliar os efeitos da concentração de amido $\left(C_{\text {Amido }}\right.$, $x_{1}$ ) e da temperatura $\left(T, x_{2}\right)$ de operação dos biorreatores sobre o rendimento da hidrólise foi feito um planejamento estrela do tipo fatorial $2^{2}$, como está apresentado na Tabela 3. Para facilitar a compreensão dos resultados, foram usadas a metodologia de otimização por análise de superfícies de respostas (RSM) e a avaliação do modelo por metodologia de análise de variâncias (BARROS NETO; SCARMINIO; BRUNS, 2001, BIAZUS et al., 2005). A codificação das variáveis utilizadas neste trabalho foi a seguinte: (Equação 3)

$x_{1}=\frac{C_{\text {Amido }}-15}{5}$ (3a) e $x_{2}=\frac{T-45}{10}$ (3b)

\section{Resultados e discussão}

Na Figura 1, observa-se que o tempo de hidrólise do amido pela a-amilase está entre 20 a mais que 200 minutos, ou seja, ele variou com a concentração de amido e temperatura do processo. Isso demonstra que a hidrólise do amido, usando-se as amilases do tipo FORILASE NTL, é rápida. Ferreira et al. $(2005,2006)$ citaram que as amilases de malte de milho hidrolisam o amido de mandioca em cerca de 20 a 30 horas.

A Tabela 3 apresenta os ensaios realizados e seus respectivos valores de rendimento de hidrólise experimentais, antecedidos do planejamento fatorial usado neste trabalho. Nota-se que o rendimento da hidrólise do amido solúvel esteve sempre acima dos $40 \%$, chegando a alcançar valores próximos aos $80 \%$ no ensaio a $45^{\circ} \mathrm{C}$ e 22,07 g. L $^{-1}$ de amido solúvel. Lima et al. (2001) afirmam que não é possível a completa hidrólise do amido por a ou $\beta$-amilases, pois elas não conseguem quebrar ligações $\alpha-1,6$ das amilopectinas, que é um polímero de glicose semelhante à amilose, diferenciando desta por suas ramificações. Os rendimentos obtidos neste trabalho são bastante superiores aos citados pela literatura. Por exemplo, Ferreira et al. (2005, 2006) citam que alcançaram um valor próximo dos $30 \%$ para amido de mandioca hidrolisado por amilases de malte de milho a $65^{\circ} \mathrm{C}$, Neves et al. (2006) observaram que o rendimento do processo de hidrólise do amido de trigo com amilase de micro-organismos foi $27,3 \%$, quando trabalhou em nível reduzido de temperatura $\left(55^{\circ} \mathrm{C}\right)$ e $14,8 \%$, quando elevou a temperatura $\left(75^{\circ} \mathrm{C}\right)$. Leonel e Cereda (2000) apresentaram rendimento semelhante ao de Ferreira et al. $(2005,2006)$ também para a hidrólise do amido de mandioca.

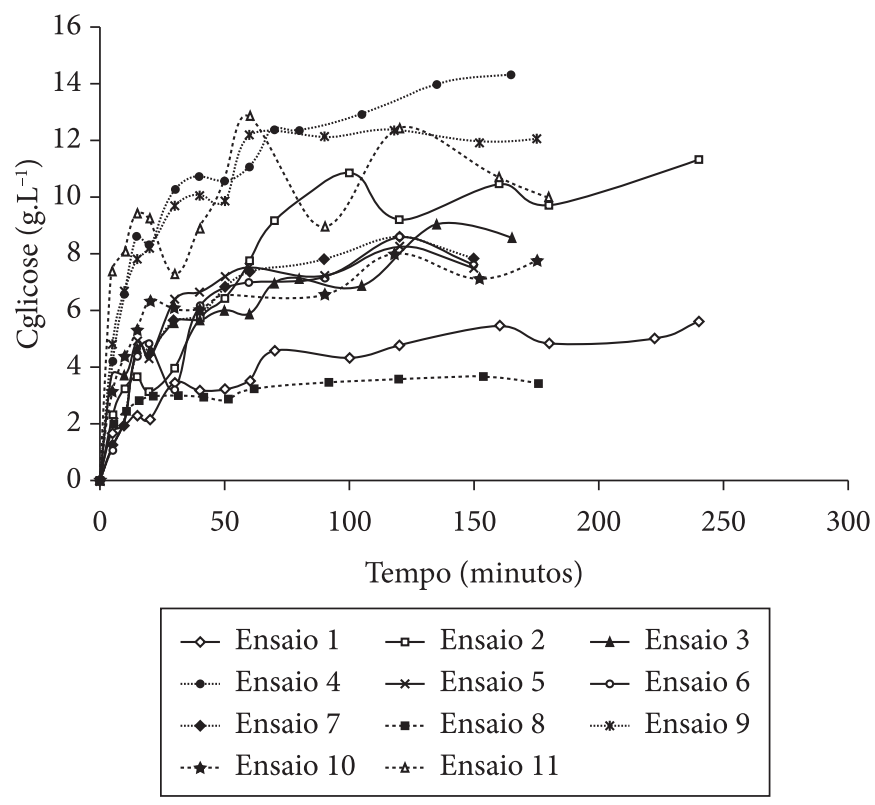

Figura 1. Curvas de hidrólise de amido pelas amilases do tipo FORILASE NTL a pH 4,8 .

Tabela 3. Matriz de planejamento do experimento de hidrólise do amido solúvel e seus devidos resultados experimentais.

\begin{tabular}{|c|c|c|c|c|c|c|}
\hline \multirow[t]{2}{*}{ Ensaios } & \multicolumn{2}{|c|}{$\begin{array}{l}\text { Concentração de } \\
\text { amido }\end{array}$} & \multicolumn{2}{|c|}{ Temperatura } & \multicolumn{2}{|c|}{$\begin{array}{l}\text { Rendimento da } \\
\text { hidrólise }\end{array}$} \\
\hline & $\mathrm{x}_{1}$ & $\mathrm{C}_{\text {Amido }}\left(\mathrm{g} \cdot \mathrm{L}^{-1}\right)$ & $\mathrm{x}_{2}$ & $\mathrm{~T}\left({ }^{\circ} \mathrm{C}\right)$ & $\% \mathrm{R}_{\text {Hidrolise }}$ & \pm \\
\hline 1 & -1 & 10 & -1 & 35 & 46,341 & 3,422 \\
\hline 2 & 1 & 20 & -1 & 35 & 45,623 & 4,028 \\
\hline 3 & -1 & 10 & 1 & 55 & 69,636 & 9,033 \\
\hline 4 & 1 & 20 & 1 & 55 & 59,452 & 4,087 \\
\hline 5 & 0 & 15 & 0 & 45 & 43,120 & 2,622 \\
\hline 6 & 0 & 15 & 0 & 45 & 47,167 & 4,312 \\
\hline 7 & 0 & 15 & 0 & 45 & 46,254 & 3,952 \\
\hline 8 & $-1,414$ & 7,930 & 0 & 45 & 55,809 & 5,162 \\
\hline 9 & 1,414 & 22,07 & 0 & 45 & 80,480 & 9,908 \\
\hline 10 & 0 & 15 & $-1,414$ & 30,86 & 41,128 & 4,0903 \\
\hline 11 & 0 & 15 & 1,414 & 59,14 & 65,490 & 8,943 \\
\hline
\end{tabular}


A Tabela 4 apresenta o resultado da avaliação do ajuste do modelo empírico utilizado (Equação 4) nos dados experimentais. De acordo com Barros Neto, Scarminio e Bruns (2001) e Biazus et al. (2005), para que um modelo possa ser significativo estatisticamente, é necessário que $F_{\text {calc (5.5) }}>$ $F_{\text {tab }(5,5)}$ e, para que ele esteja ajustado aos dados experimentais, é necessário que $F_{\operatorname{calc}(3,2)}<F_{\operatorname{tab}(3,2)}$, e o coeficiente de correlação deve estar se aproximando de 1,0 . Sendo assim, o modelo é preditivo e pode ser usado para descrever significativamente os dados experimentais.

A Equação 4 é o modelo ajustado aos dados experimentais e para melhor descrever o comportamento do rendimento da hidrólise enzimática do amido solúvel, sob influência da concentração de amido $\left(C_{\text {Amido }}, x_{1}\right)$ e da temperatura $\left(T, x_{2}\right)$.

$$
\begin{aligned}
& \% R_{\text {Hidrolise }}=45,514+1,2357 \cdot x_{1}+8,9478 \cdot x_{2}+ \\
& +8,0811 \cdot x_{1}^{2}+3,1546 \cdot x_{2}^{2}-2,3665 \cdot x_{1} \cdot x_{2}
\end{aligned}
$$

A Figura 2 mostra a superfície de resposta obtida pela equação do modelo ajustado. Nota-se que ambos os fatores possuem grande influência sobre o resultado da hidrólise do amido. Nos pontos centrais da concentração, há uma queda brusca no rendimento da hidrólise, principalmente a baixas temperaturas. Em temperaturas elevadas, o rendimento esteve sempre acima dos $70 \%$, sendo que a condição ótima se dá para concentrações de amido nos extremos e as maiores temperaturas usadas neste trabalho, ou seja, de $55-59,1{ }^{\circ} \mathrm{C}$ e nas concentrações de amido entre 7,9-10 ou 20-22 g.L.-

A Figura 3 apresenta as curvas de fermentação dos mostos contendo amido de mandioca a 2,2 e 5\%, mostrando os teores de Açúcares Redutores (AR) e alcoólicos medidos pelos dois métodos usados. Como se vê, há pouca diferença entre as medidas feitas pelos métodos usados. Ambas as fermentações foram concluídas no quinto dia, já que suas concentrações de AR iniciais eram semelhantes. No entanto, percebe-se que houve uma produção maior de álcool quando se usou um teor maior de amido de mandioca.

O teor apresentado pela fermentação com $5 \%$ de amido foi de $3,4^{\circ} \mathrm{GL}$, enquanto que o teor com $2,2 \%$ de amido foi de $2,7^{\circ} \mathrm{GL}$, como está apresentado na Tabela 5. Isto provavelmente aconteceu por que as leveduras optaram por fermentarem somente a sacarose, por gastarem menos energia neste processo e facilitar o seu desenvolvimento sem necessitar de adaptação.

Tabela 4. Análise de variância do modelo ajustado.

\begin{tabular}{lcccc}
\hline \multicolumn{1}{c}{$\begin{array}{c}\text { Fonte de } \\
\text { variação }\end{array}$} & $\begin{array}{c}\text { Soma } \\
\text { quadrática }\end{array}$ & $\begin{array}{c}\text { Graus de } \\
\text { liberdade }\end{array}$ & $\begin{array}{c}\text { Média } \\
\text { quadrática }\end{array}$ & Fcalc \\
\hline Regressão & 1047,4 & 5 & 209,48 & \\
Resíduos & 153,14 & 5 & 30,628 & $6,840^{\mathrm{a}}$ \\
Falta de ajuste & 144,13 & 3 & 48,042 & \\
Erro puro & 9,011 & 2 & 4,506 & $10,66^{\mathrm{b}}$ \\
Total & 1200,5 & 10 & & \\
\multicolumn{2}{c}{87,24} \\
\% de variância explicada $=$ & \multicolumn{2}{c}{99,25} \\
\multicolumn{2}{c}{0,9340} \\
\hline
\end{tabular}

$\mathrm{F}_{\mathrm{tab}(5,5)} \mathrm{a}=5,05^{\mathrm{a}}$ e $\mathrm{F}_{\text {tab }(3,2)}=19,28^{\mathrm{b}}$. Fonte: Barros Neto, Scarminio e Bruns (2001).

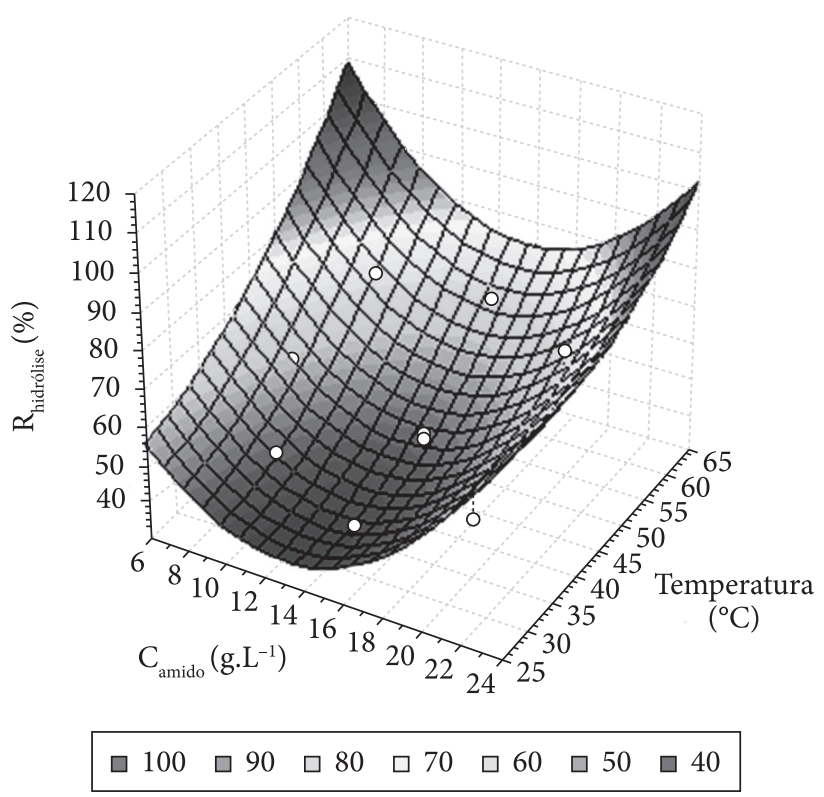

Figura 2. Superfície de resposta para avaliar os efeitos da concentração de amido e temperatura do biorreator sobre o rendimento da hidrólise do amido por $\alpha$-amilases (FORILASES NTL ${ }^{\oplus}$ ).

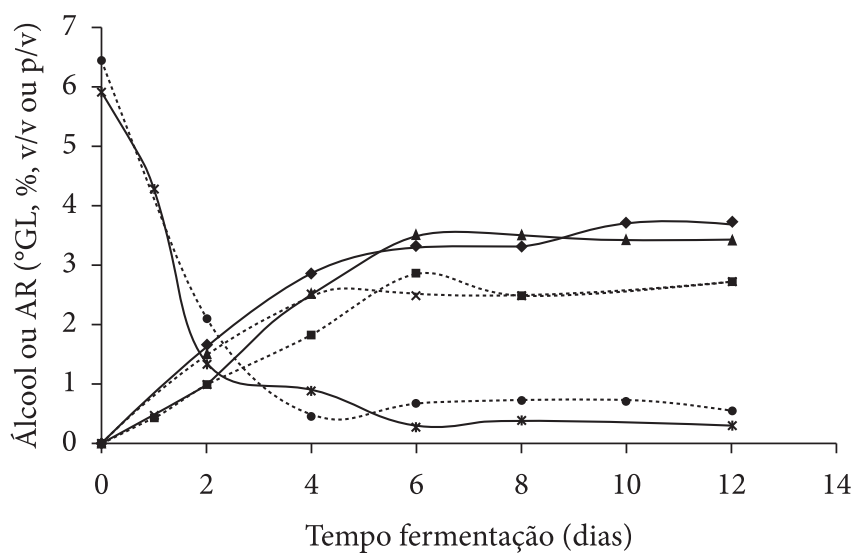

$\begin{array}{ll}\rightarrow \text { Álcool em }{ }^{\circ} \mathrm{GL} 5 \% \text { amido } & * \text { Álcool em }{ }^{\circ} \mathrm{GL} 2,2 \% \text { amido } \\ \rightarrow \text { Álcool }(\%, \mathrm{v} / \mathrm{v}) 5 \% \text { amido } & \rightarrow \text { Álcool (\%,v/v) 2,2\% amido } \\ \rightarrow \text { AR 2,2\% amido } & \rightarrow \text { AR amido 5\% }\end{array}$

Figura 3. Curvas de fermentação do amido de mandioca.

Tabela 5. Resultados das análises dos fermentados de mandioca.

\begin{tabular}{lcc}
\hline Análise (por $100 \mathrm{~mL})$ & $2,2 \%$ Amido & $5 \%$ Amido \\
\hline Extrato seco $(\mathrm{g})$ & $3,363 \pm 0,844$ & $1,536 \pm 0,209$ \\
Cinzas $(\mathrm{g})$ & $0,563 \pm 0,129$ & $0,998 \pm 0,886$ \\
AR $(\mathrm{g})$ & $0,305 \pm 0,001$ & $0,572 \pm 0,006$ \\
ART $(\mathrm{g})$ & $0,980 \pm 0,004$ & $0,668 \pm 0,005$ \\
1 - Álcool $\left({ }^{\circ} \mathrm{GL}\right)^{\mathrm{a}}$ & $2,71 \pm 0,05$ & $3,42 \pm 0,05$ \\
2 - Álcool $(\mathrm{mL})$ & $2,73 \pm 0,12$ & $3,71 \pm 0,80$ \\
1 - Rendimento & $32,7 \pm 0,05$ & $32,9 \pm 0,05$ \\
2 - Rendimento & $41,5 \pm 3,6$ & $45,0 \pm 9,7$ \\
\hline
\end{tabular}

Os índices 1 e 2 são para distinguir as análises com alcoômetro Gay Lussac da densimétrica, enquanto que o super escrito "a" indica que foi usado o erro do alcoômetro nestes valores. 
Provavelmente, pouco amido tenha sido consumido nesta fermentação, o que se nota pelo alto valor do estrato seco (a 103$105^{\circ} \mathrm{C}$ ), que, praticamente, se iguala ao valor do amido inicial junto com os nutrientes inorgânicos adicionados e a massa de mandioca que não continha amido ( $28 \%$ do farelo). Já para a fermentação contendo $5 \%$ de amido, a pequena quantidade de sacarose favoreceu a fermentação, pois forçou a levedura a se adaptar ao meio, para poder sobreviver e, assim, produziu uma maior quantidade de álcool e reduziu a quantidade de sólidos totais ao final do processo.

O rendimento alcoólico diferenciou em valores, quando se comparam os métodos utilizados, mas não variou muito entre as duas fermentações, alcançando $45 \%$. Este foi semelhante aos $39 \%$ obtidos por Ferreira et al. $(2005,2006)$, que utilizaram $10 \%$ de amido de mandioca hidrolisados por amilases de malte de milho a pH 5 e $65^{\circ} \mathrm{C}$, e obtiveram, após fermentação, um rendimento alcoólico de $39 \%$. Estes valores são tidos como bons, já que, de acordo com Reguly (1996), o máximo teórico dificilmente é alcançado $(51,111)$. O rendimento obtido neste trabalho foi superior aos apresentados por Neves et al. (2006). E como cada tonelada de mandioca produz entre 2-3,4 vezes mais álcool que a cana-de-açúcar, pode-se afirmar que seu uso na obtenção de álcool combustível é muito promissor.

\section{Conclusões}

A amilase do tipo FORILASE NTL ${ }^{\circ}$ mostrou-se uma boa atividade de hidrólise do amido solúvel, conseguindo uma total conversão entre 20-200 minutos e rendimentos que chegaram a alcançar os $80 \%$ em conversão de amido a $\mathrm{AR}$ (em termos de glicose).

A análise RSM mostrou que nos pontos centrais da concentração há uma queda brusca no rendimento da hidrólise e que em temperaturas elevadas o rendimento esteve sempre acima dos $70 \%$, sendo que a condição ótima se dá para concentrações de amido nos extremos e as maiores temperaturas usadas neste trabalho, ou seja, de $55-59,1{ }^{\circ} \mathrm{C}$ e nas concentrações de amido entre $7,9-10$ ou $20-22$ g. $\mathrm{L}^{-1}$.

O rendimento da fermentação alcoólica esteve perto dos $45 \%$ sendo superior a alguns citados pela literatura e do máximo teórico. Sendo assim, o emprego do hidrolisado de amido de mandioca na produção de álcool mostrou-se viável e ele pode ser fermentado, elevando o rendimento da produção das indústrias sucroalcooleiras.

\section{Agradecimentos}

Os autores agradecem à FAPESP (São Paulo - SP) pelo auxílio financeiro.

\section{Referências bibliográficas}

ASCAR, J. M. Alimentos: Aspectos bromatológicos e legais: análise percentual. São Leopoldo, RS: UNISINOS Editora, 1985. p. 243-252.

BARROS NETO, B.; SCARMINIO, I. S.; BRUNS, R. E. Como fazer experimentos: pesquisa e desenvolvimento na ciência e na indústria. Campinas, SP: EDUNICAMP,2001. 406 p. (Livros - Textos).

BIAZUS, J. P. M. et al. Optimization of drying process of Zea mays malt to use as alternative source of amylolytics enzymes. Brazilian Archives of Biology and Technology, v. 48, n. especial, p.185-190, 2005.

CADOGAN, A.; HANKS, J. Microbiology \& biotechnology: biology advances studies. Croacia: Nelson, 1995.

FERREIRA, G. B. et al. Characterizing of obtaining process of a manioc spirit. In: SIMPÓSIO INTERNACIONAL DE PRODUCCÍON DE ALCOHOLES Y LEVADURAS, 5, 2005.

FERREIRA, G. B. et al. Produção de álcool a partir da hidrólise do amido de mandioca por amilases do malte de milho. Revista SODEBRAS, 2006. (on-line).

FOGARTY, W. M.; KELLY, C. T. Topics in Enzyme and Fermentation Biotechnology. [S.l.]: J. Wiley and Sons, 1979. v. 3.

LEONEl, M.; CEREDA, M. P. Avaliação da concentração de pectinase no processo de hidrólise-sacarificação do farelo de mandioca para obtenção de etanol. Ciência e Tecnologia de Alimentos, v. 20, n. 2, 2000. (on-line).

LIMA, U. A. et al. Processos Fermentativos e Enzimáticos. São Paulo: Ed. Edgard Blücher, 2001. 598 p. v. 3. (Biotecnologia Industrial).

MENEZES, T. J. B. Etanol, o Combustível do Brasil. São Paulo: Agronômica Ceres, 1980.

MILLER, G. L. Use of dinitrosalicylic acid reagent for determination of reducing sugar. Analytical Chemistry, v. 31, n. 3, p. 426-428, 1959.

NEVES, M. A. et al. Production of alcohol by simultaneous saccharification and fermentation of low-grade wheat flour. Brazilian Archives of Biology and Technology, v. 49, n. 3, p. 481-490, 2006.

OLIVEIRA, M.; VASCONCELOS, Y. Revolução no canavial. Pesquisa FAPESP, v. 122, p. 62-70, 2006

REGULY, J. C. Biotecnologia dos processos fermentativos. [S.1.]: Editora Universitária/UFPel, 1996. 330 p.

REGULY, J. C. Biotecnologia dos processos fermentativos: fermentações industriais e biomassa celular. Pelotas: Editora Universitária, 1998. 224 p.

REGULY, J. C. Biotecnologia dos processos fermentativos: produção de enzimas e engenharia das fermentações. Pelotas: Editora Universitária, 2000. 218 p.

SLEIMAN, M.; VENTURI FILHO, W. G. Utilização de extratos de malte na fabricação de cervejas: Avaliação físico-química e sensorial. Brazilian Journal Food and Techonology, v. 7, n. 2, p. 145-153, 2004.

WISEMAN, A. Handbook of enzyme biotechnology. 2 ed. New York, EUA: John Wiley Sons, 1987. 